\title{
FUNGAL LEACHING OF IRON ORE: ISOLATION, CHARACTERIZATION AND BIOLEACHING STUDIES OF PENICILLIUM VERRUCULOSUM
}

\author{
Neha Chaudhary, Trina Banerjee, Neha Ibrahim and G. Sibi \\ Department of Biotechnology, \\ Indian Academy Degree College, Centre for Research and Post Graduate Studies, Bangalore, India
}

Received 2014-08-02; Revised 2014-09-02; Accepted 2014-09-20

\begin{abstract}
Pyrometallurgical and hydrometallurgical technologies for recovery of metals from low grade ores require high energy and capital costs. Use of microorganisms in leaching of mineral ores is gaining importance due to the implementation of stricter environmental rules. Microbes convert metal compounds into their water soluble forms and are biocatalysts of leaching processes. This study was performed to isolate and characterize iron solubilizing fungi from low grade iron ore for bioleaching process. Soil samples from iron mine area were used for isolation of iron solubilizing fungi and two fungal species (NTS-1 and NTS-2) were obtained from enrichment culture method. Bioleaching experiments were carried out in batch culture to determine the iron solubilising efficiencies of the isolates. Inductively Coupled Plasma-Optical Emission Spectroscopy (ICP-OES) was used to determine the solubilized iron concentration and strain NTS-2 exhibited 40\% higher iron solubilization than strain NTS-1. The strain was subjected to 18S-ITS sequence of rRNA studies and the phylogenetic analyses justify a taxonomic position for the strain as a member of Penicillium verruculosum. The isolated strain could be used in solubilizing iron from low grade ores as an efficient, economical and eco-friendly alternative to conventional operations.
\end{abstract}

Keywords: Bioleaching, Iron Ore, Penicillium, Microbial Leaching, Biomining

\section{INTRODUCTION}

Biohydrometallurgy is the interaction between metals and microbes results in the conversion of insoluble metal forms into soluble forms (Mishra and Rhee, 2014) which can be recovered through conventional methods (Brandl and Faramarzi, 2006). Bioleaching allows the cycling of metals similar to that of biogeochemical cycles there by reducing the demand for resources such as ores (Krebs et al., 1997). The use of microorganisms in leaching of mineral ores is an efficient, economical and ecofriendly alternative to conventional hydrometallurgical operations (Gentina and Acevedo,
1985). Recovery of metals from low-grade ores using pyrometallurgical and hydrometallurgical technologies requires high energy and capital costs. Microorganisms are used to extract many minerals and current developments in mineral processing using microbes are targeting other base metals (Johnson, 2008). Microbial leaching is increasingly applied for metal recovery from low grade ores that cannot be processed economically by conventional methods (Bosecker, 1997). Several studies were reported on role of microorganisms in sorption of metals (Langley and Beveridge, 1997), dissolution of metals (Banfield and Hamers, 1997; Barker et al., 1997; Bennett et al., 2001) and mineral crystallization (Fortin et al., 1997). Studies, Bangalore, India 
The forms of iron found in nature depend on the $\mathrm{pH}$ and oxygen concentration. At neutral $\mathrm{pH}$ and in the presence of oxygen, ferrous iron $\left(\mathrm{Fe}^{2+}\right)$ is oxidized to ferric iron $\left(\mathrm{Fe}^{3+}\right)$ and forms highly insoluble $\mathrm{Fe}(\mathrm{OH})_{3}$ (Manchee, 1977). Microbes convert metal compounds into their water soluble forms and are biocatalysts of leaching processes. Many microbes have mechanisms that enable access to ion from poorly soluble forms (Martino et al., 2004). One possible way to obtain iron from low grade ores is through the microbial leaching. This study was aimed at isolating the iron solubilising fungi for bioleaching of iron ores and characterization of the potential strain by $18 \mathrm{~S}$ rRNA studies.

\section{MATERIALS AND METHODS}

\subsection{Isolation of Microorganisms}

The initial source of inoculum was top soil collected from Ponda iron mine ( $\left.15^{\circ} 40^{\prime} \mathrm{N}, 74^{\circ} 01^{\prime} \mathrm{E}\right)$, Goa. Mineral salts media containing $0.4 \mathrm{~g}$ each of $\left(\mathrm{NH}_{4}\right)_{2} \mathrm{SO}_{4}, \mathrm{~K}_{2} \mathrm{HPO}_{4}$ and $\mathrm{MgSO}_{4} \cdot 7 \mathrm{H}_{2} \mathrm{O}(\mathrm{pH}, 2.5)$ per litre was used for enrichment culture. Media containing $1 \%(\mathrm{w} / \mathrm{v})$ iron ore material was inoculated with serially diluted mine soil sample and incubated in shaking $(140 \mathrm{rpm})$ conditions at $32^{\circ} \mathrm{C}$. The grown fungal culture was purified by streak plate method for bioleaching experiments.

\subsection{Bioleaching Studies}

From the enrichment culture, two fungal strains (strain NTS-1 and NTS-2) were isolated and screened for their ability to solubilize iron ore. Bioleaching studies were carried out in $250 \mathrm{~mL}$ of modified Silverman and Lundgren medium containing $(\mathrm{g} / \mathrm{L})$ : $\left(\mathrm{NH}_{4}\right)_{2} \mathrm{SO}_{4}, 3.0$; $\mathrm{KCl}, 0.1 ; \mathrm{K}_{2} \mathrm{HPO}_{4}, 0.5 ; \mathrm{MgSO}_{4} \cdot 7 \mathrm{H}_{2} \mathrm{O}, 0.5 ; \mathrm{Ca}\left(\mathrm{NO}_{3}\right)_{2}$, $0.01, \mathrm{pH}$ adjusted to 2.5 with dilute hydrochloric acid under batch process. $1 \%$ iron ore was used as substrate and the strains were inoculated followed by incubation at $32^{\circ} \mathrm{C}$ with shaking $(140 \mathrm{rpm})$ for 28 days. The contents of the flasks were filtered and added with $10 \mathrm{~mL}$ of concentrated $\mathrm{HNO}_{3}$ and refluxed for about $1 \mathrm{~h}$ at $95^{\circ} \mathrm{C} \pm 5^{\circ} \mathrm{C}$. The process was repeated until the digestion was completed and the solution was evaporated to $5 \mathrm{~mL}$. The solutions were cooled and $10 \mathrm{~mL}$ of concentrated $\mathrm{HCl}$ was added into each flask and refluxed for about 15 min to remove the nitrous fumes. The digested sample solutions were cooled and $20 \mathrm{~mL}$ of deionized water was added into each flask. The digested solutions were filtered into $50 \mathrm{~mL}$ volumetric flask and the volume was made up to the mark with deionized water to determine soluble iron concentration.

\subsection{ICP-OES Analysis}

Inductively Coupled Plasma-Optical Emission Spectroscopy (ICP-OES) with radial torch equipped with argon saturation assembly was used for the determination of iron (Thermo Scientific ICAP 6000 series). High purity (99.99\%) argon was used as plasma, auxiliary and nebulizer gas. The gas flows were kept at 15.0 $\mathrm{L} \mathrm{min}^{-1}$ for plasma, $1.50 \mathrm{~L} \mathrm{~min}^{-1}$ for auxiliary and $0.56 \mathrm{~L} \mathrm{~min}^{-1}$ for nebulizer. Radio frequency power of the plasma generator was $1.35 \mathrm{~kW}$. Vertical height of the plasma was fixed at $7 \mathrm{~mm}$. Sample uptake time of 30.0 $\mathrm{sec}$, delay time of $5 \mathrm{sec}$, rinse time of $10 \mathrm{sec}$, initial stabilization time of $10 \mathrm{sec}$ and time between replicate analyses of $5 \mathrm{sec}$ were maintained throughout the studies for ICP-OES. $100 \mathrm{~mL}$ of ammonium ferrous sulphate (1000 ppm) was prepared and added with $2 \mathrm{~mL}$ of nitric acid solution and used as stock solution. From the stock solution $10 \mathrm{~mL}$ was taken and diluted to $100 \mathrm{~mL}$ with $2 \%$ of nitric acid solution to get a final concentration of $100 \mathrm{ppm}$. From the working solution (100 ppm), respective concentration was prepared using $2 \%$ nitric acid solution. All the observation of emission was recorded at $259.94 \mathrm{~nm}$ which corresponds to the most sensitive wavelength of iron. The solubilized iron in the filtrates of species NTS-1 and NTS-2 was quantified and the fungal strain which showed maximum solubilisation of iron was chosen for further identification studies.

\subsection{Isolation of Fungal DNA}

DNA from species NTS-2 was isolated using DNAzol reagent. In brief, $1 \mathrm{~mL}$ of DNAzol reagent was added to $1-3 \times 10^{7}$ cells in suspension (volume $<0.1 \mathrm{~mL}$ ). The cells were lysed by gentle pipetting and pelleted again followed by resuspend in one volume of cold $\left(4^{\circ} \mathrm{C}\right)$ hypotonic solution $(20 \mathrm{mM}$ Tris $\mathrm{HCl}, \mathrm{pH} 8.0,10 \mathrm{mM}$ EDTA). The cells were pelleted at 4,000 rpm for $10 \mathrm{~min}$ $\left(4^{\circ} \mathrm{C}\right)$ and the supernatant was discarded. The DNA was precipitated from the lysate by the addition of $0.5 \mathrm{~mL}$ of $100 \%$ ethanol per $1 \mathrm{~mL}$ of DNAzol reagent used for the isolation. The samples were mixed by inversion and stored at room temperature for 1-3 min. The DNA precipitate was removed by spooling with a pipette tip and was swirled onto the tip and attaches it to the tube wall near the top of the tube by gently sliding the DNA off the tip. The supernatant was carefully decanted, leaving the DNA pellet near the top of the tube. The tubes were placed upright for $1 \mathrm{~min}$ and the remaining lysate was aspirated from the bottom of the tubes. The DNA precipitate was washed twice with $0.8-1.0 \mathrm{~mL}$ of $75 \%$ ethanol and air dried. 


\subsection{S-ITS Sequence of rRNA Based Molecular Technique}

The isolated DNA was checked on $0.8 \%$ agarose gel for purity and quality. 18S rRNA gene primers were used to amplify $\sim 1.1 \mathrm{~kb}$ gene from the genomic DNA isolated. The PCR product obtained was gel purified followed by quantification and sequenced by 18S-ITS sequence of rRNA based molecular technique. Sequence data obtained was subjected to BLAST with NCBI gene databases based on maximum identity score.

\subsection{Phylogenetic Analyses}

Phylogenetic analyses were carried out using Clustal W software 1.8. The Neighbour-Joining (NJ) method was used to infer the evolutionary history of strain NTS-2 and identified through molecular and phylogenetic approaches. The ITS phylogenetic analyses and the closest relatives obtained from GenBank supported the major lineages in NJ analysis identified the genera of strain NTS-2.

\section{RESULTS AND DISCUSSION}

In order to obtain iron solubilization strain, soil dilution was prepared and then spread on mineral salts medium by enrichment technique. Consequently, two fungal strains were obtained and named as strain NTS-1 and NTS-2 after 15 days of incubation at $32^{\circ} \mathrm{C}$. Macroscopic appearance of strain NTS-1 revealed that colonies were powdery and green in colour. Microscopic observation exhibited hyaline septate hyphae with vesicle formation. Conidiophores were covering only the partial upper surface with flask shaped phialides. Strain NTS-2 colonies were seen as velvety, gray green colour and the reverse was yellowish. Under the microscope, septate hyaline hyphae with branched conidiophores, phialides and conidia were observed. Phialides form brush like clusters at the tip of conidiophores. Bioleaching studies of the isolates were carried out in $9 \mathrm{k}$ medium (Silverman and Lundgren, 1959) for a period of 28 days to compare the efficiencies in iron solubilization. ICP-OES analysis of the filtrates from bioleaching experiments revealed that strain NTS-2 solubilized maximum iron from the ore (Table 1) with a final concentration of $71.7 \mathrm{ppm}$ (1534 cts/S and $0.179 \%$ RSD) followed by $28.7 \mathrm{ppm}$ from strain NTS-1 (613.1 Cts/S and $0.236 \%$ RSD). The iron solubilization of control flasks were found as 20.92 ppm. From the results, strain NTS-2 has shown 40\% higher iron solubilization (Fig. 1 and 2) than strain NTS-1 and hence used for further identification studies. Genomic DNA from strain NTS2 was isolated and 18S rRNA primers were used for PCR amplification. 18S-ITS sequence of $\sim 1.1 \mathrm{~kb}$ subjected to BLAST analysis showed that strain NTS-2 fell within the radiation of cluster comprising of Penicillium species. The results obtained from morphology, gene sequence and phylogenetic analysis justify a taxonomic position for the strain as a member of Penicillium verruculosum (Fig. 3) with $100 \%$ similarity.

There is a growing interest to adopt microbiological process over conventional technologies to recover valuable metals (Gadd, 2000; Rawlings and Johnson, 2007). The ability of microorganisms in mineral leaching has opened a new avenue bioleaching from metal ores (Gupta and Sant, 1970). Microbial leaching has potential uses such as remediation of mining sites and treatment of metal containing waste products (Bosecker, 2001). Microorganisms play a prominent role in the solubilization of metals and minerals in the ecosystems under appropriate environmental conditions.

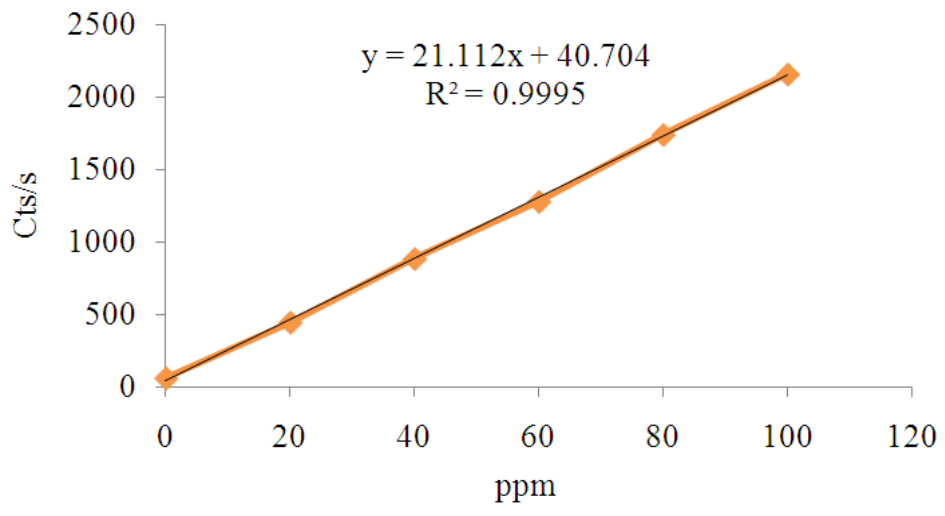

Fig. 1. Calibration curve for iron 


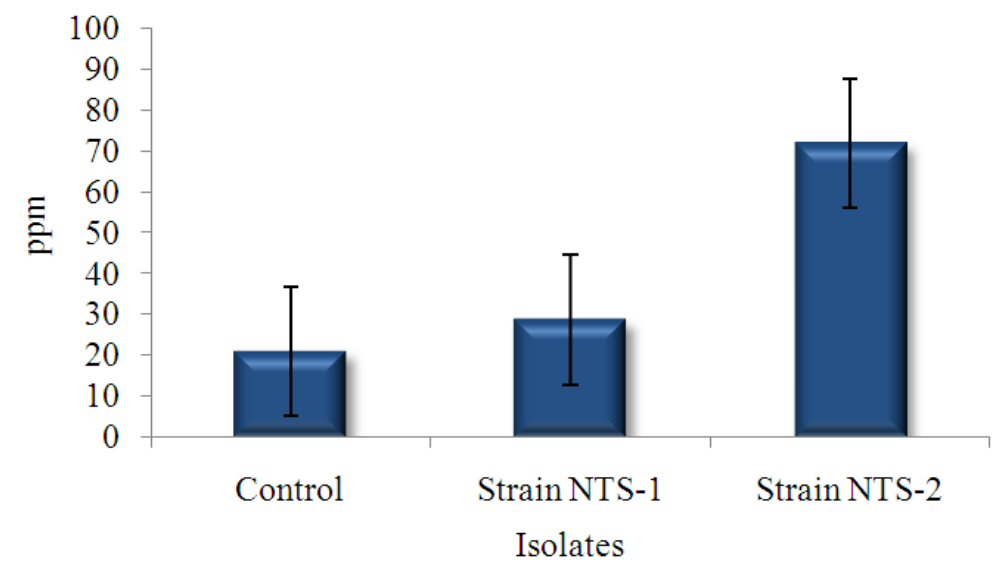

Fig. 2. Iron solubilization by the isolates

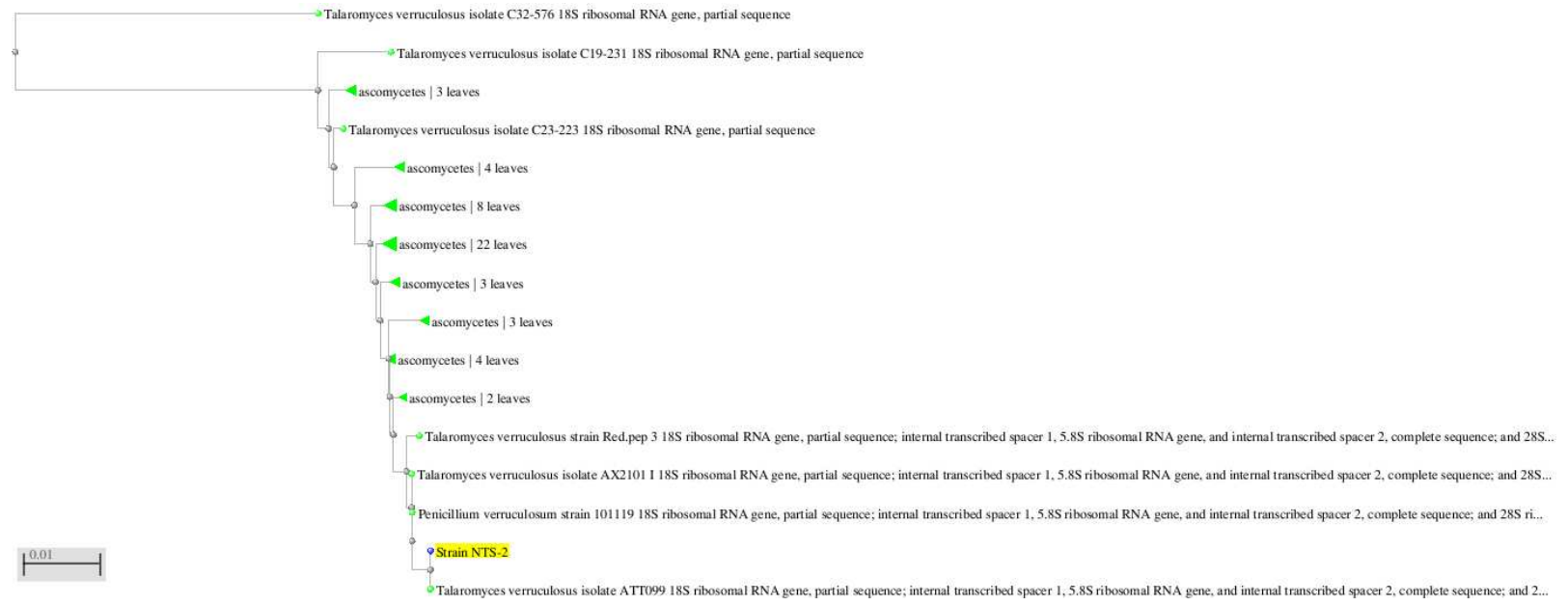

Fig. 3. Neighbour joining tree, based on $18 \mathrm{~S}$ rRNA gene sequences showing the phylogenetic positions of

Table 1. ICP-OES analysis of samples at $\mathrm{A}_{259} 94$

\begin{tabular}{lrcc}
\hline Sample & \multicolumn{1}{c}{ Cts/S } & Std Dev & \%RSD \\
\hline Std-1 $(0 \mathrm{ppm})$ & 61.687 & 1.140 & 1.8520 \\
Std-2 $(20 \mathrm{ppm})$ & 446.290 & 2.240 & 0.5030 \\
Std-3 $(40 \mathrm{ppm})$ & 885.820 & 0.729 & 0.0824 \\
Std-4 $(60 \mathrm{ppm})$ & 1280.700 & 4.300 & 0.3359 \\
Std-5 $(80 \mathrm{ppm})$ & 1743.000 & 14.000 & 0.7853 \\
Std-6 $(100 \mathrm{ppm})$ & 2160.400 & 13.700 & 0.5874 \\
Strain NTS-1 & 613.100 & 1.430 & 0.2363 \\
Strain NTS-2 & 1534.000 & 2.010 & 0.1161 \\
Control & 447.500 & 0.810 & 0.1789 \\
\hline
\end{tabular}

Identification of potential microbes is a major part of the developmental process in bioleaching. Two methods are commonly used for the isolation, characterization and utilization of mineral-associated microbes in biohydrometallurgical processes. The first method is the direct enrichment culture method where the mineral is added to a defined medium for the purpose of isolation and leaching of the mineral (Goebel and Stackerbrandt, 1994). The other method involves direct isolation from the surface of the mineral and subsequent utilisation of the isolates for leaching processes (Delvasto et al., 2008). This study followed the first method which allowed the isolation of two fungal isolates namely NTS1 and NTS-2. The genus identified in this study has been isolated previously (Sabat and Gupta, 2009; Rezza et al., 1997; Adeleke et al., 2010).

The leaching ability of metal appears to be dependent on the type of strains used. Fungi may interact with metalcontaining ores depending on their metal tolerance and ability to influence the metal mobilization (Fomina et al., 2005). Fungus has been used for the bioleaching in 
which Penicillium and Aspergillus are commonly applied in metal recovery (Olson et al., 2003). In this study, two fungal strains were identified based on colonial and microscopic appearance as Aspergillus and Penicillium. From the bioleaching studies, potential iron solubilising strain was identified and further confirmed as Penicillium verruculosum by 18 S ITS sequencing. Acidophilic microorganisms that take part in dissolution of metals are autotrophic with low $\mathrm{pH}$ values hence the medium during the isolation was set at $\mathrm{pH}-2.5$. Bioleaching processes are mediated by the metabolites produced from microbial metabolic process (Vasan et al., 2001; Burford et al., 2003; Burgstaller and Schinner, 1993; Ghorbani et al., 2007) which could aid the solubilization of complex minerals (Gadd, 1999). The final $\mathrm{pH}$ of the medium after the appropriate incubation period was found as 3.0 which revealed the production of organic acids by the isolate. From an industrial perspective it is essential that biomining microorganisms must able to grow at low $\mathrm{pH}$ and tolerate high concentrations of acid for better solubilization of minerals and metals. In this study, $P$. verruculosum (strain NTS-2) was able to tolerate low pH values and exhibited higher solubilization rates from the iron ore.

\section{CONCLUSION}

This study involves the isolation and characterization of iron solubilising fungi from mine soil sample by enrichment culture technique. 18S-ITS sequencing studies followed by phylogenetic analysis justified a taxonomic position for the strain as a member of Penicillium verruculosum which exhibited $40 \%$ more iron solubilization among the isolates. Isolation of microorganisms from mine areas is suitable approach to identify microbes that can solubilize metal ions for bioleaching process. This study is limited to the identification of iron solubilising fungi from low grade ores and further work is needed to evaluate the role of fungal secondary metabolites involved in the leaching process. The scope of this study extends by using Penicillium verruculosum in solubilising iron from low grade ores as an efficient, economical and eco-friendly alternative to conventional operations.

\section{REFERENCES}

Adeleke, R., E. Cloete and D. Khasa, 2010. Isolation and identification of iron ore-solubilising fungus. South African J. Sci., 106: 43-49. DOI: 10.4102/sajs.v106i9/10.254
Banfield, J.F. and R.J. Hamers, 1997. Processes at minerals and surfaces with relevance to microorganisms and prebiotic synthesis. Rev. Mineral. Geochem., 35: 81-122.

Barker, W.W., S.A. Welch and J.F. Banfield, 1997. Geomicrobiology of Silicate Mineral Weathering. In: Geomicrobiology: Interactions between Microbes and Minerals, Banfield, J.F. and K.H. Nealson (Eds.), Mineralogical Society of America, Washington, DC, ISBN-10: 0939950456, pp: 391-428.

Bennett, P.C., J.R, Rogers, W.J. Choi and F.K. Hiebert, 2001. Silicates, silicate weathering and microbial ecology. Geomicrobiol. J., 18: 3-19. DOI: 10.1080/01490450151079734

Bosecker, K., 1997. Bioleaching: Metal solubilisation by microorganisms. FEMS Microbiol. Rev., 20: 591604. DOI: 10.1111/j.1574-6976.1997.tb00340.x

Bosecker, K., 2001. Microbial leaching in environmental clean-up program. Hydrometallurgy, 59: 245-248. DOI: 10.1016/S0304-386X(00)00163-8

Brandl, H. and M.A. Faramarzi, 2006. Microbe-metalinteractions for the biotechnological treatment of metal-containing solid waste. China Particul., 4: 93-97. DOI: 10.1016/S1672-2515(07)60244-9

Burford, E.P., M. Fomina and G.M. Gadd, 2003. Fungal involvement in bioweathering and biotransformation of rocks and minerals. Mineral. Magazine, 67: 11271155. DOI: 10.1180/0026461036760154

Burgstaller, W. and F. Schinner, 1993. Leaching of metals with fungi. J. Biotechnol., 27: 91-116. DOI: 10.1016/0168-1656(93)90101-R

Delvasto, P., A. Valverde, A. Ballester, J.A. Munoz and F. Gonzalez et al., 2008. Diversity and activity of phosphate bioleaching bacteria from a highphosphorus iron ore. Hydrometallurgy, 92: 124-129. DOI: 10.1016/j.hydromet.2008.02.007

Fomina, M.A., I.J. Alexander, J.V. Colpaert and G.M. Gadd, 2005. Solubilization of toxic metal minerals and metal tolerance of mycorrhizal fungi. Soil Biol. Biochem., 37: 851-866. DOI: 10.1016/j.soilbio.2004.10.013

Fortin, D., F.G. Ferris and T.J. Beveridge, 1997. Surface-mediated mineral development by bacteria. Rev. Mineral. Geochem., 35: 161-180.

Gadd, G.M., 1999. Fungal production of citric and oxalic acid: Importance in metal speciation, physiology and biogeochemical processes. Adv. Microbial Physiol., 41: 47-92. DOI: 10.1016/S0065-2911(08)60165-4 
Gadd, G.M., 2000. Bioremedial potential of microbial mechanisms of metal mobilization and immobilization. Current Opin. Biotechnol., 11: 271279. DOI: $10.1016 / \mathrm{S} 0958-1669(00) 00095-1$

Gentina, J.C. and F. Acevedo, 1985. Microbial ore leaching in developing countries. Trends Biotechnol., 3: 86-89. DOI: 10.1016/01677799(85)90087-3

Ghorbani, Y., M. Oliazadeh, A. Shahvedi, R. Roohi and A. Pirayehgar, 2007. Use of some isolated fungi in biological Leaching of Aluminum from low grade bauxite. Afr. J. Biotechnol., 6: 1284-1288.

Goebel, B.M. and E. Stackebrandt, 1994. Cultural and phylogenetic analysis of mixed microbial populations found in natural and commercial bioleaching environments. Applied Environ. Microbiol., 60: 1614-1621. PMID: 7517131

Gupta, R.C. and B.R. Sant, 1970. Beneficiation of low grade ores by microbial leaching. J. Sci. Industrial Res., 29: 372-377.

Johnson, D.B., 2008. Biodiversity and interactions of acidophiles: Key to understanding and optimizing microbial processing of ores and concentrates. Trans. Nonferrous Metals Society China, 18: 1367-133. DOI: $10.1016 /$ S1003-6326(09)60010-8

Krebs, W., C. Brombacher, P.P. Bosshard, R. Bachofen and H. Brandl, 1997. Microbial recovery of metals from solids. FEMS Microbiol. Rev., 20: 605-617. DOI: 10.1016/S0168-6445(97)00037-5

Langley, S. and T.J. Beveridge, 1997. Effect of O-side chain lipopolysaccharide chemistry on metal binding. Applied Environ. Microbiol., 65: 489-498. PMID: 9925573

Manchee, R.J., 1977. Bacterially assisted plants process for leaching of uranium ore in geology. Mining and Extractive Process of Uranium. London.
Martino, E., S. Cerminara, L. Prandi, B. Fubini and S. Perroto, 2004. Physical and biochemical interactions of soil fungi with asbestos fibers. Environ. Toxicol. Chem., 23: 938-944. PMID: 15095889

Mishra, D. and Y.H. Rhee, 2014. Microbial leaching of metals from solid industrial wastes. J. Microbiol., 52: 1-7. DOI: 10.1007/s12275-014-3532-3

Olson, G.J., J.A. Brierley and C.L. Brierley, 2003. Bioleaching review part B: Progress in bioleaching: Applications of the microbial processes by the mineral industries. Applied Microbiol. Biotechnol., 63: 249-257. DOI: 10.1007/s00253-003-1404-6

Rawlings, D.E. and D.B. Johnson, 2007. The microbiology of biomining: Development and optimization of mineral oxidizing microbial consortia. Microbiology, 153: 315-324. DOI: 10.1099/mic.0.2006/001206-0

Rezza, I., E. Salinas, V. Calvente, D. Benuzzi and M.I. Sanz de Tosetti, 1997. Extraction of lithium from spodumene by bioleaching. Lett. Applied Microbiol.. 25: 172-176. DOI: 10.1046/j.1472765X.1997.00199.X

Silverman, M.P. and D.G. Lundren, 1959. Studies on the chemoautotrophic iron bacterium Ferrobacillus ferrooxidans: An improved medium and a harvesting procedure for screening high cell yields. J. Bacteriol., 77: 642-647. PMCID: 290434

Sabat, J. and N. Gupta, 2009. Iron ore solubilization by Penicillium restrictum: Effect of carbon source and incubation days. Am. Eurasian J. Agronomy, 2: 43-44.

Vasan, S.S., J.M. Modak and K.A. Natarajan, 2001. Some recent advances in the bioprocess of Bauxite. Int. J. Mineral Process., 62: 173-186. DOI: 10.1016/S0301-7516(00)00051-X 